УДК 615.322

\title{
ПЕРСПЕКТИВЫ СОВЕРШЕНСТВОВАНИЯ СТАНДАРТОВ КАЧЕСТВА ПЛОДОВ ГРЕЙПФРУТА (CĪTRUS PARADĪSI MACFAD)
}

\author{
Минаева Олеся Рафиковна \\ ФГАОУ ВО Первый МГМУ имени И.М. Сеченова \\ Минздрава России (Сеченовский Университет) \\ Нестерова Ольга Владимировна \\ д.ф.н, профессор \\ Бирюкова Наталья Викторовна \\ директор
} преподаватель РЦ «Медицинский Сеченовский Предуниверсарий»

Аннотация: в статье приводится анализ контента научной литературы и нормативной документации (ГОСТ 34307-2017 «Плоды цитрусовых культур. Citrus fructus. Specifications») характеризующей состав биологически активных веществ и нормы их содержания в плодах грейпфрута. Выявлен устойчивый интерес исследователей к всестороннему изучению данного широко культивируемого фрукта. Вместе с тем, следует обратить внимание на отсутствие в нормативной документации показателей, способных помимо пищевых характеристик, показать содержание витаминов, микроэлементов, веществ флавоноидной природы, наличие которых и обуславливает биологическую ценность Citrus paradise Macfad. Показана важность дальнейшей разработки и включения норм содержания витаминов и микроэлементов в стандарты качества, характеризующие плоды грепфрута.

Ключевые слова: растения рода Cītrus paradīsi, БАВ, аскорбиновая кислота, ликопин, кремний, бор, методы анализа, ГОСТ.

\section{PROSPECTS FOR IMPROVING THE QUALITY STANDARDS OF GRAPEFRUIT (CĪTRUS PARADĪSI MACFAD)}

Minaeva Olesya Rafikovna Olga Vladimirovna Nesterova Biryukova Natalia Viktorovna

\begin{abstract}
: the article provides an analysis of the content of scientific literature and regulatory documentation (GOST 34307-2017 "Fruits of citrus crops. Citrus
\end{abstract}


fructus. Specifications") describing the composition of biologically active substances and the norms of their content in grapefruit fruits. The steady interest of researchers in a comprehensive study of this widely cultivated fruit is revealed. At the same time, it is necessary to pay attention to the absence in the regulatory documentation of indicators that can, in addition to food characteristics, show the content of vitamins, trace elements, substances of flavonoid nature, the presence of which determines the biological value of Citrus paradise Macfad. The importance of further development and inclusion of norms for the content of vitamins and trace elements in the quality standards that characterize the fruit of grepfruit is shown.

Key words: plants of the genus Cìtrus paradīsi, BAS, ascorbic acid, lycopene, silicon, boron, methods of analysis, GOST.

Анализ научной литературы показал отсутствие единого мнения у ученых относительно родины грейпфрута. Данный тропический фрукт встречается в странах Средиземноморья, произрастает в Японии, Китае, в Южной Америке и на Кавказе. Первое упоминание о грейпфруте относится к XVIII веку. В то время британские мореплаватели в первый раз заметили большие деревья, богатые крупными плодами. Непосредственно из-за изобилия плодов, собранных в гроздья, похожие на виноград, грейпфрут и приобрел собственное название (в переводе с английского «грейпфрут»«виноградный фрукт»). В первый раз деревья грейпфрута были описаны на острове Барбадос в 1750 году, потом на Ямайке в 1814 году. Родным краем культурного грейпфрута принято считать Индию, а также Центральную Америку. В начале 19 века (1880 год) растение было перевезено в Флориду, а спустя сто лет грейпфрут стал одним из лидеров международного рынка фруктов. [1,2]

Ряд исследователей полагают, что грепфрут представляет собой гибрид помпельмуса (прочие наименования шеддок, помело) и сладкого апельсина, появившегося внезапно уже в Новом Свете, в Западной Индии. Согласно суждению же других, грейпфрут произошел от зёрен шеддока, прежде скрещенного со сладким апельсином, но ни один исследователь не сумел воспроизвести его искусственным путем. [3]

Позднее европейцы выяснили, что имеется ряд видов грейпфрута - его плоды могут быть розоватыми, желтоватыми и практически белоснежными. Также чем более розового оттенка в кожуре и мякоти грейпфрута, тем выше его вкусовые характеристики. [4] 
В России грейпфрут выращивается с 1911 года. В литературе также встречается наименование грейпфрута - помпельмус гроздевидный, обусловленное тем, что плоды растут в большей степени гроздьями по 3-12 штук в кисти. Отсюда и английское наименование, обозначающее в переводе "виноградный плод", что совсем не связано с вкусовыми характеристиками. Плоды как правило большие (до 500 г), покрыты достаточно толстой кожурой с оттенком от светлого вплоть до интенсивного оранжевого тона, однако вне зависимости от тона с особым немного горьковатым запахом. [5]

Эксперты отмечают, что чистый цитрусовый запах грейпфрута помогает при депрессии, а также апатии, потому что активизирует заинтересованность к жизни, повышает настроение и ощущение полноты жизни, кроме того обостряет память и внимание. Ко всему остальному, свежевыжатый грейпфрутовый нектар оказывает на организм тонизирующее действие, восстанавливает перистальтику ЖКТ, печени и желчного пузыря. Нектар в особенности рекомендован в период выздоровления с целью укрепления иммунитета - после физического и интеллектуального переутомления. [6]

Масло грейпфрута применяют в кондитерском, а также ликероводочном производстве, но кроме того в парфюмерии с целью изготовления различных одеколонов и туалетной воды. $[8,7]$

Плоды употребляют в пищу в большей степени сырыми, во фруктовых и пряных салатах, так они обретают душистый, утонченный привкус. Из грейпфрутов также готовят джем, и, безусловно, изготовляют соки. Для косметических процедур применяется помимо нектара и мякоть, а также кожуру плодов. $[9,10]$

Однако, вкусовые характеристики не определяют ценность данных плодов, как перспективного лекарственного растительного сырья, обладающего широким спектром фармакологической активности. Основная значимость данного плода, по мнению многих авторов - уникальный состав биологически активных веществ. [11, 12]

Целью данного исследования является всестороннее изучение научной литературы, патентной и нормативно-правовой документации, отражающей современное состояние изучения качественного и количественного содержания БАВ в составе грейпфрута. 


\section{Материалы и методы исследования}

Для реализации поставленной цели нами были использованы документальный, системный и структурно-логический методы, контентанализ, мониторинг научных статей в периодических изданиях. Был проработан ГОСТ 34307-2017 «Плоды цитрусовых культур. Citrus fructus. Specifications» и проведен системный анализ научных публикаций, посвященных качественному и количественному анализу содержания БАВ в грейпфруте свежем.

\section{Результаты и обсуждение}

После определения БАВ в составе грейпфрута, можно сделать некоторый анализ. Химический анализ содержащихся в составе грейпфрута свежего веществ (рис. 1):

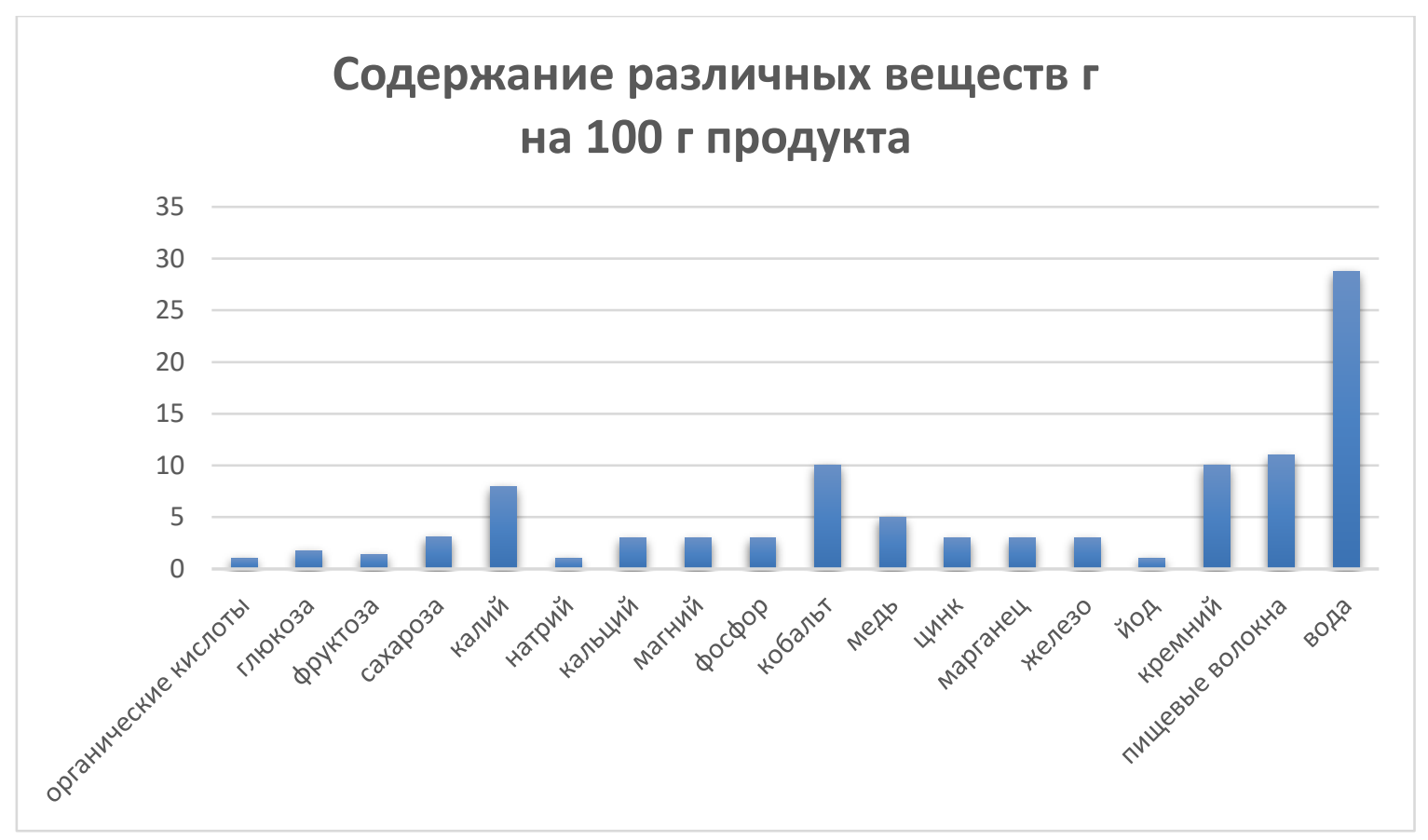

\section{Рис. 1. Различные вещества в составе грейпфрута свежего}

В грейпфруте содержится большое количество витамина А (ретинола), витамина С (аскорбиновой кислоты), ликопина, бета-каротина и витаминов группы В, в особенности В9 (фолиевой кислоты) (рис. 2). 


\section{Содержание витаминов, мкг на 100 г продукта}

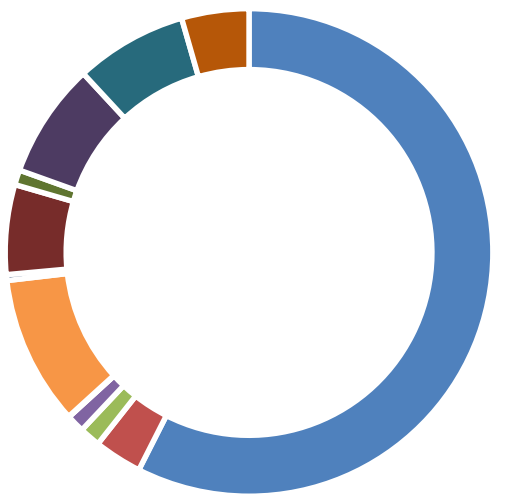

\begin{tabular}{|c|c|c|c|}
\hline$-A$ & $-\mathrm{C}$ & 匹 ликопин & - B5 \\
\hline$=\mathrm{B} 6$ & - B9 & - $\mathrm{PP}$ & - альфа-каротин \\
\hline - B7 & - B4 & - лютеин + & - бета-криптоксантин \\
\hline
\end{tabular}

\section{Рис. 2. Витамины в составе грейпфрута свежего}

Исследуя содержание минералов, а именно макроэлементов, можно отметить, что больше всего кремния, калия, натрия и фосфора (рис. 3).

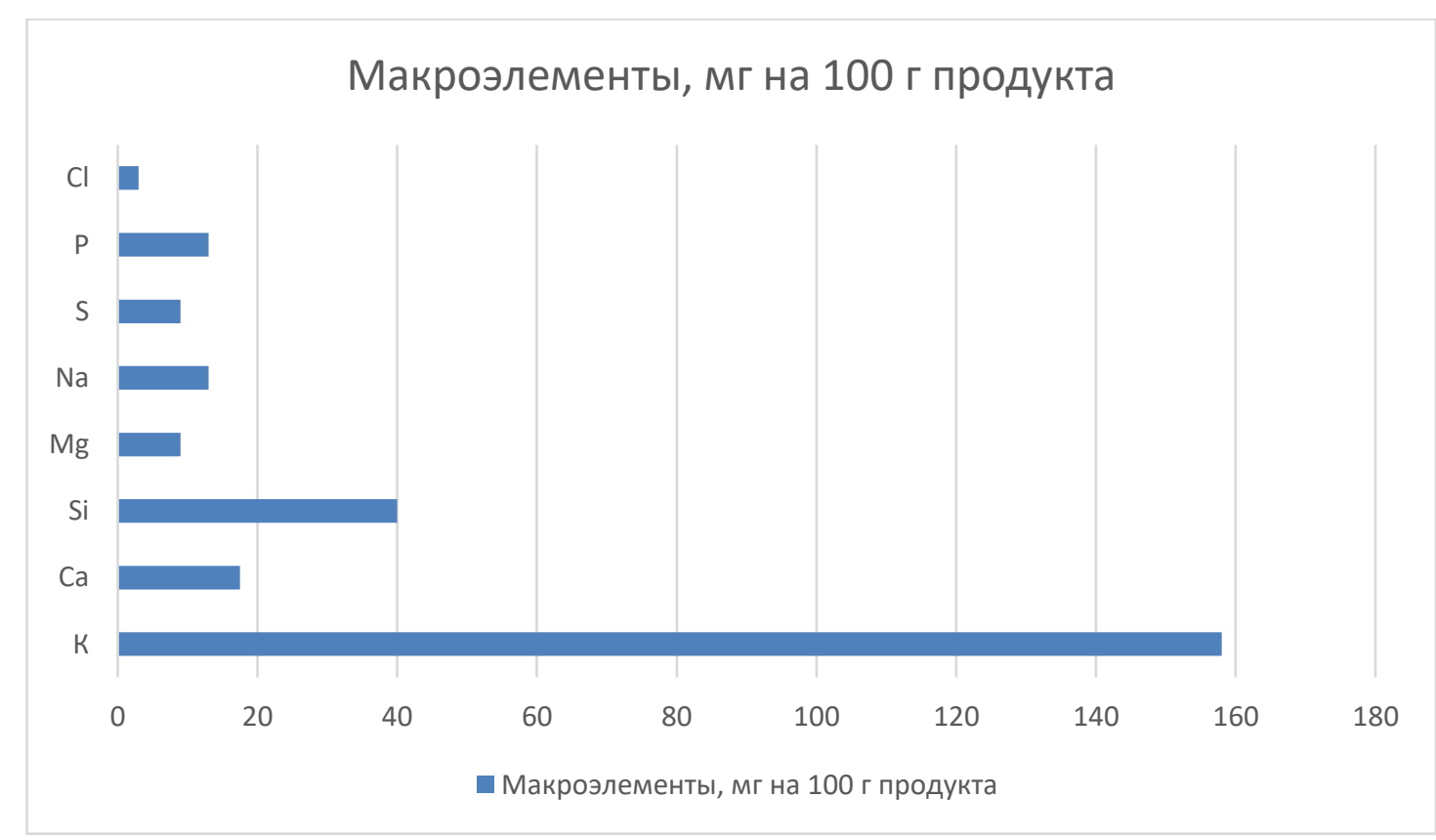

Рис. 3. Макроэлементы в составе грейпфрута свежего

При исследовании содержания микроэлементов в составе грейпфрута, выяснено, что наибольшее количество бора, алюминия, рубидия, меди, марганца и цинка (рис. 4). 
Микроэлементы и ультрамикроэлементы, мкг на 100 г продукта

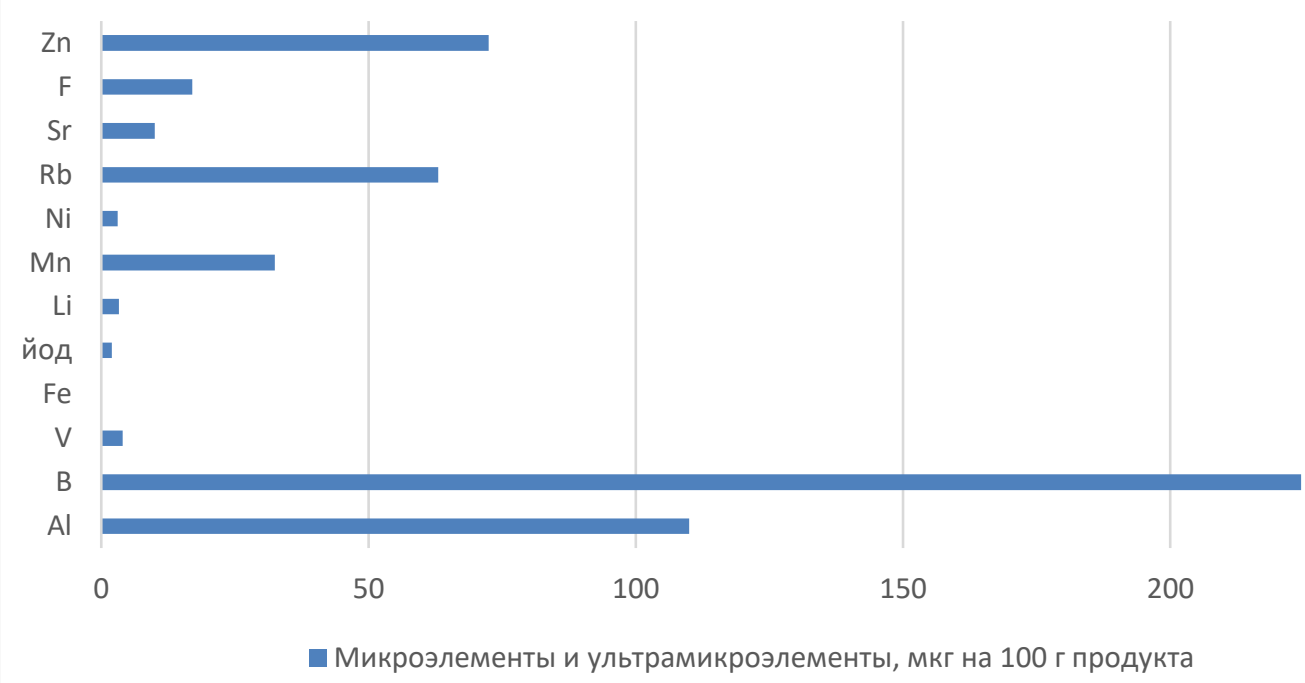

250

Рис. 4. Макроэлементы в составе грейпфрута свежего

Содержание белков, жиров и углеводов представлено на диаграмме (рис. 5). Больше всего содержится углеводов, а именно глюкозы, фруктозы и сахарозы.

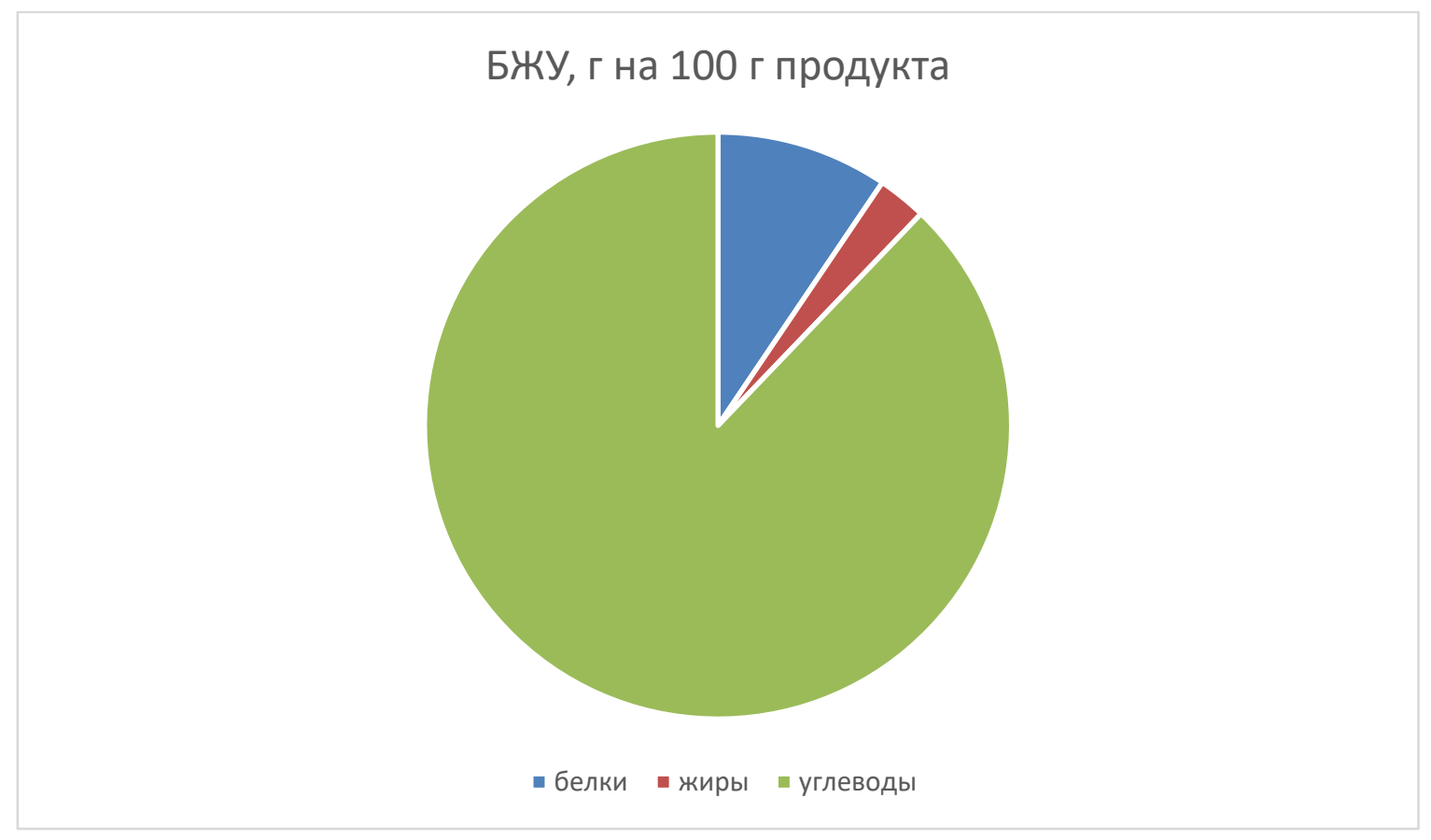

Рис. 5. Белки, жиры и углеводы в составе грейпфрута свежего 
Таким образом, в литературе встречается достаточное количество публикаций, содержащих данные о проведенных исследованиях количественного содержания в сырье различных веществ, белков, жиров, углеводов, макроэлементов, микроэлементов и ультрамикроэлементов. Существенная часть научных работ посвящается анализу аскорбиновой кислоты, ликопина, а также микроэлементов кремния, бора. Полученные авторами данные позволяют начать системную работу, направленную на определение норм содержания данных веществ, с последующим включением в усовершенствованную нормативную документацию (рис. 6).

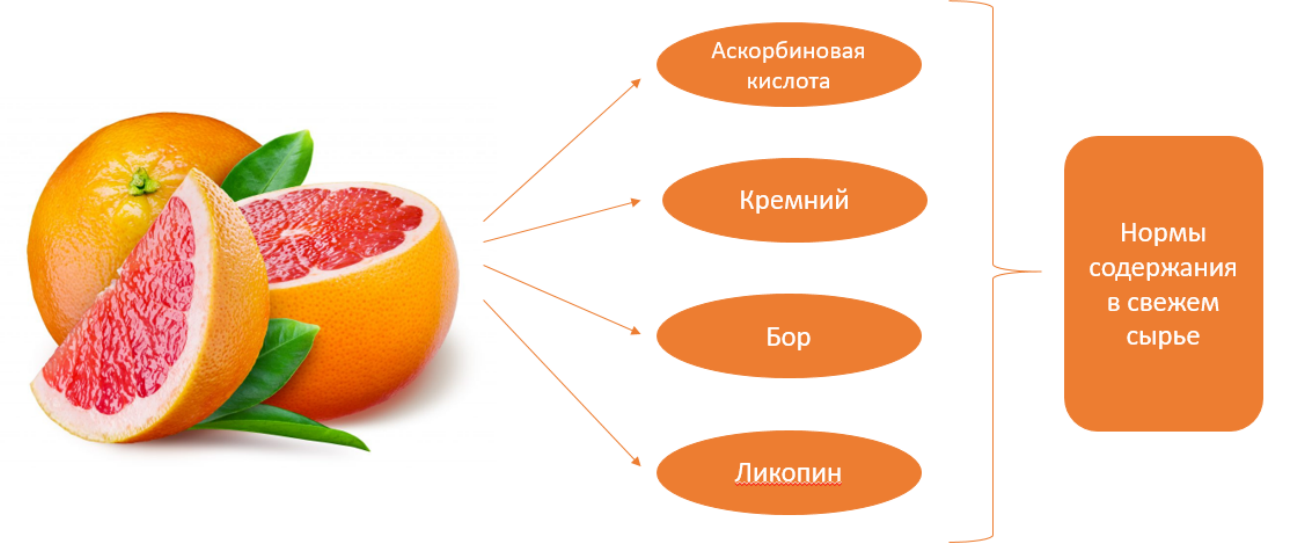

\section{Рис. 6. Планируемые нормативы содержания БАВ в плодах грейпфрута}

Вывод. Анализ научной литературы и нормативной документации, характеризующей состав биологически активных веществ и нормы их содержания в плодах грейпфрута показывает устойчивый интерес исследователей к всестороннему изучению данного популярного фрукта. Вместе с тем, следует отметить отсутствие в нормативной документации показателей, способных помимо пищевых характеристик, показать содержание витаминов, микроэлементов, веществ флавоноидной природы, наличие которых и обуславливает биологическую ценность данной культуры. Показана необходимость включения норм содержания витаминов и микроэлементов в стандарты качества, характеризующие плоды грейпфрута.

\section{Список литературы}

1. Ademosun A.O., Oboh G. Anticholinesterase and antioxidative prorerties of water-extractable phytochemicals from some citruspeets - J. Basic Clin. Physiol. Pharmacol. 2014, May 1. 
2. Ahmad S.F., Zoheir K.M., Abdel-Hamied H.E., Ashour A.E., Bakheet S.A., Attia S.M., Abd-Allah A.R. Amelioration of autoimmune arthritis by naringin through modulation of T regulatory cells, 2014.

3. Bailey D.G. Predicting clinical relevance of grapefruit-drug interactions^ ${ }^{\wedge}$ a complicated process - J. Clin. Pharm. Ther. 2016, oct 6.

4. Bodiford A.B., Kessler F.O, Fermo J.D., Ragucci K.R. Elevated international normalized ratio with the consumption of grapefruit and use of warfarin - SAGE open Med. Case Rep. 2013, nov 19.

5. Bojanic Z.Z., Bojanic N.Z., Bojanic V.V. [Drug interactions with grapefruit] - Med. Pregl/ 2012, Nov-Dec.

6. Castro-Vazquez L., Alañón M.E., Rodríguez-Robledo V., PérezCoello M.S., Hermosín-Gutierrez I., Díaz-Maroto M.C., Jordán J., Galindo M.F., ArroyoJiménez M.del M. Bioactive Flavonoids, Antioxidant Behaviour, and Cytoprotective Effects of Dried Grapefruit Peels (Citrus paradisi Macf.) - Oxid. Med. Cell. Longev. 2016, 201630

7. Colon M., Nerin C. Role of catechins in the antioxidant capacity of an active film containing green tea, green coffee, and grapefruit extracts - J. Agric. Food Chem. 2012, Oct 3

8. Daher C.F., Abou-Khalil J., Baroody G.M. Effect of acute and chronic grapefruit, orange, and pineapple juice intake on blood lipid profile in normolipidemic rat - Med. Sci. Monit. 2005, Dec.

9. de la Garza A.L., Etxeberria U., Palacios-Ortega S., Haslberger A.G., Aumueller E., Milagro F.I., Martínez J.A. Modulation of hyperglycemia and TNF $\alpha-$ mediated inflammation by helichrysum and grapefruit extracts in diabetic $\mathrm{db} / \mathrm{db}$ mice - Food Funct. 2014, Sep.

10. Diab K.A. In Vitro Studies on Phytochemical Content, Antioxidant, Anticancer, Immunomodulatory, and Antigenotoxic Activities of Lemon, Grapefruit, and Mandarin Citrus Peels - Asian. Pac. J. Cancer. Prev. 2016.

11. Diaconu C.H., Cuciureanu M., Vlase L., Cuciureanu R. Food-drug interactions: grapefruit juice - Rev. Med. Chir. Soc. Med. Nat. Iasi. 2011, Jan-Mar.

12. Gamboa-Gómez C., Salgado L.M., González-Gallardo A., RamosGómez M., Loarca-Piña G., Reynoso-Camacho R. Consumption of Ocimum sanctum L. and Citrus paradisi infusions modulates lipid metabolism and insulin resistance in obese rats - Food Funct. 2014, May. 
13. Девис М., Остин Дж., Патридж Д. Витамин С. Химия и биохимия. М. : Мир. - 1999.; 6. Денисов Л.И., Лобарева Л.С., Якушева Е.О. / Терапевтический архив. - 1994.

14. В.И. Дейнеко «Научные ведомости», Каротиноиды: строение, биологические функции и перспективы применения, 2006. №8/

15. Каротиноиды: строение, биологические функции и перспективы применения / В.И. Дейнеко // Научные ведомости. 2006.

16. Каротиноиды. Биологическая активность / Дадали В.А. [и др.] // Вопросы питания. 2011.

17. Всесоюзный симпозиум "Биологически активные соединения элементов IV Б группы”, Тез. докл. - Иркутск. - 1975.

18. Schwarz K., Miene D. Ironth pomotihg eff ects of silicon in rats // Nuture. - 1972.

19. Yagovtsev, A.V. Study of Effect of Zirconia-Graphite Material Composition on its Properties / A.V. Yagovtsev, N.V. Obabkov, I.D. Kashcheev // Refractories and Industrial Ceramics. - 2014. - №5.

20. Валкер, Д.М. Исследование отношения 10В/11В методом ЯМР спектроскопии / Д.М. Валкер, Р.М. Смит, Р.Дж. Старкс. - В кн.: Бор, получение, структура и свойства. Материалы IV Международного симпозиума по бору. - М: Наука, 1974. 